This item was submitted to Loughborough's Research Repository by the author.

Items in Figshare are protected by copyright, with all rights reserved, unless otherwise indicated.

\title{
A spatial autoregressive stochastic frontier model for panel data with asymmetric efficiency spillovers
}

PLEASE CITE THE PUBLISHED VERSION

http://dx.doi.org/10.1016/j.jeconom.2015.06.011

PUBLISHER

(c) Elsevier

VERSION

AM (Accepted Manuscript)

\section{PUBLISHER STATEMENT}

This work is made available according to the conditions of the Creative Commons Attribution-NonCommercialNoDerivatives 4.0 International (CC BY-NC-ND 4.0) licence. Full details of this licence are available at: https://creativecommons.org/licenses/by-nc-nd/4.0/

\section{LICENCE}

CC BY-NC-ND 4.0

\section{REPOSITORY RECORD}

Glass, Anthony, Karligash Glass, and Robin Sickles. 2015. "A Spatial Autoregressive Stochastic Frontier Model for Panel Data with Asymmetric Efficiency Spillovers". Loughborough University. https://hdl.handle.net/2134/17622. 


\title{
A Spatial Autoregressive Stochastic Frontier Model for Panel Data with Asymmetric Efficiency Spillovers
}

\author{
Anthony J. Glass*, Karligash Kenjegalieva ${ }^{\dagger}$ and Robin C. Sickles ${ }^{\ddagger}$ \\ April 2015
}

\begin{abstract}
By blending seminal literature on non-spatial stochastic frontier models with key contributions to spatial econometrics we develop a spatial autoregressive (SAR) stochastic frontier model for panel data. The specification of the SAR frontier allows efficiency to vary over time and across the cross-sections. Efficiency is calculated from a composed error structure by assuming a half-normal distribution for inefficiency. The spatial frontier is estimated using maximum likelihood methods taking into account the endogenous SAR variable. We apply our spatial estimator to an aggregate production frontier for 41 European countries over the period 1990-2011. In the application section, the fitted SAR stochastic frontier specification is used to discuss, among other things, the asymmetry between efficiency spillovers to and from a country.
\end{abstract}

Key words: Spatial Autoregressive Dependence; Stochastic Frontier Analysis (SFA); Asymmetric Directional Efficiency Spillovers; Aggregate Production; European Countries.

JEL Classification: C23; C51; D24; E23.

*School of Business and Economics, Loughborough University, Leics, UK, LE11 3TU. Email: A.J.Glass@lboro.ac.uk.

${ }^{\dagger}$ School of Business and Economics, Loughborough University, Leics, UK, LE11 3TU. Email: K.A.Kenjegalieva@lboro.ac.uk.

$\ddagger$ Corresponding author

$\S$ Department of Economics, Rice University, Houston, US, and School of Business and Economics, Loughborough University, Leics, UK, LE11 3TU. Email: rsickles@rice.edu 


\section{Introduction}

In cross-sectional and panel data modeling, the presence of omitted variable bias due to the omission of a spatial lag of the dependent variable, which captures what is referred to as spatial autoregressive (SAR) dependence in the cross-sections, has long been recognized. Among other reasons, this motivated the development of the SAR model in key contributions by Cliff and Ord $(1973 ; 1981)$, which involves augmenting the standard non-spatial specification with the weighted average of the dependent variable for neighboring units. ${ }^{1}$ This SAR term is endogenous which is accounted for using various methods in the spatial econometrics literature. For stochastic frontier models, biased parameter estimates due to the omission of the SAR variable also has implications for the efficiency scores. We therefore merge techniques used in spatial econometrics with those from the stochastic frontier literature to develop a stochastic frontier for panel data with SAR dependence. The composed error structure of stochastic frontiers consists of inefficiency and an idiosyncratic error, where we follow much of the literature on nonspatial stochastic frontiers and make distributional assumptions to distinguish between the components of the composed error.

The approach which we employ can also be easily adapted to develop a spatial error stochastic frontier model for panel data. Such a model would involve augmenting the standard non-spatial stochastic frontier with the weighted average of the spatially autocorrelated errors for neighboring units. We do not pursue such a specification here because we have a strong preference for the SAR specification. This is because although both models capture global spillovers, in the spatial error specification these spillovers relate to the latent nuisance term, whereas global spillovers in a SAR specification have a structural economic interpretation because, as will become apparent, these spillovers can be related to the independent variables. ${ }^{2}$ The marginal effects from the SAR specification are referred to as: direct (i.e. own), indirect (i.e. spillover) and total (direct plus indirect) impacts (LeSage and Pace, 2009). ${ }^{3}$

The literature on spatial stochastic frontier modeling is rather sparse. A small number

\footnotetext{
${ }^{1}$ This is based on the assumption that the spatial weights matrix is row-normalized i.e. the row sums of the spatial weights matrix sum to 1 .

${ }^{2}$ To illustrate the difference between global spillovers and local spillovers, suppose a region's set of neighbors is assumed to be based on contiguity and thus consists of the regions with whom it shares a border. Local spillovers to a region would be those from its contiguous neighbors (i.e. 1st order neighbors). Global spillovers to a region would be those that come from its contiguous neighbors, the contiguous neighbors of its neighbors (i.e. 2nd order neighbors), the contiguous neighbors of its neighbors' neighbors (i.e. 3rd order neighbors) and so on and so forth.

${ }^{3} \mathrm{~A}$ direct elasticity is interpreted in the same way as an elasticity from a non-spatial model, although a direct elasticity takes into account feedback effects (i.e. effects which pass through 1st order and higher order neighbors and back to the unit which initiated the change). An indirect elasticity can be calculated in two ways yielding the same numerical value. This leads to two interpretations of an indirect elasticity: (i) the average change in the dependent variable of all the other units following a change in an independent variable for one particular unit; or (ii) the average change in the dependent variable for a particular unit following a change in an independent variable for all the other units.
} 
of studies estimate spatial stochastic frontiers and calculate efficiency using the crosssectional specific effects. The first of these studies is due to Druska and Horrace (2004). By extending the spatial error model for cross-sectional data as set out by Kelejian and Prucha (1999), they develop a GMM spatial error stochastic frontier model with fixed effects. They then calculate time-invariant efficiency from the cross-sectional specific effects using the Schmidt and Sickles (1984) (SS from hereon) estimator. The SS efficiency estimator assumes a composed error structure which consists of time-invariant inefficiency and the idiosyncratic disturbance. The unit with the largest (smallest) fixed/random effect is placed on the concave (convex) frontier and the efficiency estimates are the exponential of the difference between the best performing unit's fixed/random effect and the corresponding effect for each of the other units in the sample. Glass et al. (2013) adopt a similar approach by following Cornwell et al. (1990) (CSS from hereon) which involves using the cross-sectional specific effects from a SAR stochastic frontier model to estimate time-variant efficiency.

We are not aware of a stochastic frontier model that accounts for global spatial dependence via the endogenous SAR variable or via the endogenous spatial autocorrelated error term; whilst also calculating efficiency from a composed error structure by making an assumption about the inefficiency distribution. Such a model which accounts for SAR dependence is therefore developed in this paper. To the best of our knowledge, Adetutu et al. (2014) is the only study that introduces a spatial relationship into a stochastic frontier model where an assumption is made about the distribution of the inefficiency component of the error structure. Their model, however, unlike the estimator we develop, overlooks global spatial dependence as they omit, for example, the endogenous SAR variable. That said, although their model specification represents a simple way of accounting for spatial interaction they limit their analysis to local spatial dependence by including only spatial lags of the exogenous variables. Such local spatial stochastic frontiers can therefore be estimated using the standard procedures for the non-spatial stochastic frontier.

The spatial stochastic frontier estimator which we present represents an alternative to using the cross-sectional specific effects from a spatial stochastic frontier to estimate efficiency. In addition, there is plenty of scope to extend the spatial stochastic frontier estimator which we develop. For example, rather than assume that the inefficiency distribution is half-normal, as we do here, we could use the time-varying decay efficiency estimator (Battese and Coelli, 1992) or assume that inefficiency follows a truncated normal distribution (e.g. Stevenson, 1980) or, alternatively, is Gamma distributed (e.g. Greene, 1990). Furthermore, the SAR stochastic frontier which we propose captures supply chain management issues across space such as outsourcing to a firm in another location or, at the aggregate level, importing from another country. This is because, for example, a SAR stochastic production frontier is such that via the spillover input elasticities, a unit's output depends on the inputs of the other units in the sample. The 
issue then is how efficiently does a unit use the inputs of other units in different locations (i.e. efficiency across space). A central feature of the SAR stochastic frontier which we develop is spatial efficiency, or in other words, efficiency spillovers, which complements the literature on estimating productivity spillovers (Chandra and Staiger, 2007; Girma, 2005; Takii, 2005; Girma and Wakelin, 2007; Girma et al., 2008).

We apply our spatial estimator to an aggregate production frontier using balanced panel data for 41 European countries over the period 1990 - 2011 and estimate the model using maximum likelihood (ML) methods. Using spatial econometric techniques to analyze country productivity has been a fertile area for research in recent years. LópezBazo et al. (2004), Egger and Pfaffermayr (2006), Ertur and Koch (2007), Koch (2008) and Pfaffermayr (2009) all extend the standard Solow (1956; 1957) neoclassical growth set-up by endogenizing technical change. They then estimate the reduced form equation for output per worker using a non-frontier SAR model or a non-frontier spatial error specification. Rather than estimate the reduced form equation for output per worker we estimate the assumed underlying spatial Cobb-Douglas technology using a stochastic frontier specification.

It is important to note that the efficiency estimates from our SAR stochastic frontier are directly comparable to the efficiency estimates from the corresponding non-spatial stochastic frontier. For such spatial and non-spatial stochastic frontiers where an assumption is made about the inefficiency distribution, the efficiencies are calculated relative to an absolute best practice frontier. In contrast, when the cross-sectional specific effects are used to calculate time-invariant efficiency, efficiency is estimated relative to the best performing unit in the sample. In addition to estimating the SAR stochastic frontier by making an assumption about the inefficiency distribution, a novel feature of our approach is how we adapt the SS method and apply it to the efficiencies to calculate time-varying relative direct, relative indirect and relative total efficiencies in order to analyze spatial efficiency. The SS method assumes efficiency is time-invariant but we adapt this approach to obtain time-varying estimates of relative direct, relative indirect and relative total efficiencies by placing the best performing unit in the sample in each time period on the frontier, where the best performing unit and thus the benchmark may change from one period to the next.

The relative direct, relative indirect and relative total efficiencies are calculated and interpreted along the same lines as the direct, indirect and total marginal effects. There are two valid ways of estimating relative indirect efficiency which yield estimates of different magnitude giving rise to asymmetric directional efficiency spillovers. In turn this leads to two estimates of total efficiency which differ in magnitude. ${ }^{4}$ Intuitively, relative

\footnotetext{
${ }^{4}$ Glass et al. (2014) show how efficiencies which are estimated using the cross-sectional specific effects from a SAR stochastic frontier can be used to compute relative direct, relative indirect and relative total efficiencies. In this paper we show that this approach to calculate relative direct, relative indirect and relative total efficiencies can also be applied to a SAR stochastic frontier when an assumption is made
} 
indirect efficiency benchmarks how successful a unit is at exporting/importing productive performance vis-à-vis its peers in the sample. For example, firms in different countries may export and import efficiency via knowledge spillovers. ${ }^{5}$

To provide an insight into the type of conclusions that can be made from the SAR stochastic frontier, the application indicates when we control for spatial dependence average efficiency of the worst performing countries in the sample (Albania, Armenia, Belarus, Moldova and Ukraine) is higher than we observe from the non-spatial stochastic frontier. This we suggest is because by controlling for spatial dependence we account for the disadvantageous location of such countries. In the application we estimate two specifications of the SAR stochastic frontier. The first SAR specification augments the non-spatial stochastic frontier with the spatial lag of the dependent variable and the second is widely referred to in the regional science, urban economics and geography literature as the spatial Durbin specification. The spatial Durbin stochastic frontier is the SAR stochastic frontier augmented with variables which only capture local spatial dependence, or in other words, spatial lags of the exogenous variables.

The remainder of this paper is organized as follows. In Section 2 we present the SAR stochastic frontier, which encompass the spatial Durbin frontier. Also in Section 2, we set out the estimation procedure which employs ML methods. In Section 3, we explain how the efficiencies from the SAR frontier can be used to compute relative direct, asymmetric relative indirect and asymmetric relative total efficiencies. The SAR stochastic frontier is applied to the case of aggregate production of European countries in Section 4 and in Section 5 we conclude.

\section{Model, Estimation and Efficiency}

\subsection{SAR Stochastic Frontier}

Consider the following SAR stochastic frontier model for panel data:

$$
\begin{aligned}
y_{i t} & =x_{i t} \beta+\delta \sum_{j=1}^{N} w_{i j} y_{j t}+v_{i t}-u_{i t}, \\
i & =1, \ldots, N ; t=1, \ldots, T .
\end{aligned}
$$

$N$ is a cross-section of units operating over a fixed time dimension $T, y_{i t}$ is an observation for the objective variable (e.g. output, profit, revenue, etc.) for the $i t h$ unit at time $t$, where lower case letters denote logged variables, $x_{i t}$ is a $(1 \times K)$ vector of exogenous

about the inefficiency distribution. Unlike Glass et al. (2014), however, we do not confine our analysis to just one way of estimating the relative indirect and relative total efficiencies.

${ }^{5}$ The literature on knowledge spillovers is vast but key references include Coe and Helpman (1995), Keller (2002) and Keller and Yeaple (2013). For other studies on knowledge spillovers see Branstetter (2001), Bottazzi and Peri (2003), Blazek and Sickles (2010) and Bahar et al. (2014). 
independent variables and $\beta$ is a vector of parameters. For the SAR stochastic frontier model, $x_{i t}$ will include variables which together with $y_{i t}$ represent the frontier technology, and $x_{i t}$ will also include any variables which shift the frontier. For example, in the case of a production frontier $x_{i t}$ will include observations for the inputs. $\sum_{j=1}^{N} w_{i j} y_{j t}$ is the endogenous spatial lag of the dependent variable which shifts the frontier technology, where $w_{i j}$ is a non-negative element of the spatial weights matrix, $W$, and $\delta$ is the SAR parameter. Eq. 1 encompasses the spatial Durbin stochastic frontier where in this case $x_{i t}$ would also include as variables which shift the frontier technology exogenous spatial lags of the non-spatial independent variables.

The error structure in Eq. 1 is $\varepsilon_{i t}=v_{i t}-u_{i t}$ and is for production, revenue, standard and alternative profit, and input distance frontiers, where $v_{i t}$ is an idiosyncratic disturbance and $u_{i t}$ represents inefficiency. The error structure for cost and output distance frontiers would be $\varepsilon_{i t}=v_{i t}+u_{i t}$. We assume that $v_{i t}$ and $u_{i t}$ are both i.i.d, and that $v_{i t} \sim N\left(0, \sigma_{v}^{2}\right)$ and $u_{i t} \sim\left|N\left(0, \sigma_{u}^{2}\right)\right|$. This asymmetric error structure is adopted directly from the classic stochastic frontier framework in Aigner et al. (1977) (ALS from hereon). Furthermore, we follow ALS and obtain the log-likelihood function for Eq. 1 by using $\sigma^{2}=\sigma_{v}^{2}+\sigma_{u}^{2}$ and $\lambda=\frac{\sigma_{u}}{\sigma_{v}}$ to reparameterize Eq. 1. As a result, $\sigma_{u}^{2}=\frac{\sigma^{2}}{1+\lambda^{2}}$ and $\sigma_{v}^{2}=\frac{\sigma^{2} \lambda^{2}}{1+\lambda^{2}}$.

$W$ captures the spatial arrangement of the cross-sectional units and also the strength of the spatial interaction between the units. $W$ is specified prior to estimation and is usually based on some measure of geographical or economic proximity. As is standard in the spatial literature, all the diagonal elements of $W$ are set to zero to rule out 'self-influence'. In addition, $W$ is normalized to have row sums of unity so that the endogenous spatial lag of the dependent variable is a weighted average of observations for the dependent variable for neighboring units which facilitates interpretation. We make the following assumptions with regards to Eq. 1. (i) $\left(I_{N}-\delta W\right)$ is non-singular and the parameter space of $\delta$ is $\left(\frac{1}{r_{\min }}, 1\right)$, where $I_{N}$ is the $(N \times N)$ identity matrix and $r_{\min }$ is the most negative real characteristic root of $W$. The inverse of the largest real characteristic root of $W$ is the upper limit of the parameter space of $\delta$. Since we use a row-normalized $W$ in the application, 1 is the largest real characteristic root of $W$ which simplifies the computation of $\log \left|I_{N}-\delta W\right|$ in the estimation (see subsection 4.1). (ii) The row and column sums of $W$ and $\left(I_{N}-\delta W\right)^{-1}$ are bounded uniformly in absolute value before $W$ is row-normalized. As a result of this assumption the spatial process for the dependent variable has a 'fading' memory (Kelejian and Prucha, 1998; 1999). 


\subsection{Estimation of the SAR Frontier and Efficiency}

Assuming the panel is balanced, the log-likelihood function associated with Eq. 1 is:

$$
\begin{aligned}
L L\left(y \mid \beta, \delta, \lambda, \sigma^{2}\right)= & -\frac{N T}{2} \log \left(2 \pi \sigma^{2}\right)+T \log \left|I_{N}-\delta W\right|-\frac{1}{2 \sigma^{2}} \sum_{i=1}^{N} \sum_{t=1}^{T} \varepsilon_{i t}^{2}+ \\
& \sum_{i=1}^{N} \sum_{t=1}^{T} \log \left[1-\Phi\left(\frac{\varepsilon_{i t} \lambda}{\sigma}\right)\right],
\end{aligned}
$$

where $\Phi$ is the standard normal cumulative distribution function and $T \log \left|I_{N}-\delta W\right|$ is the scaled logged determinant of the Jacobian of the transformation from $\varepsilon_{t}$ to $y_{t}$. Such transformations are undertaken in ML estimation of non-spatial and spatial models to derive the probability density function of the dependent variable from the probability density function of the disturbance. For ML estimation of spatial models such as Eq. 1 , as is standard in the spatial econometrics literature, the transformation from $\varepsilon_{t}$ to $y_{t}$ takes into account the endogeneity of the spatial lag of the dependent variable (Anselin, 1988, p 63; Elhorst, 2009).

The partial derivatives of the log-likelihood function are given in Eqs. $3-6$ :

$$
\begin{aligned}
\frac{\partial L L}{\partial \beta} & =\frac{1}{\sigma^{2}} \sum_{i=1}^{N} \sum_{t=1}^{T} x_{i t} \varepsilon_{i t}+\frac{\lambda}{\sigma} \sum_{i=1}^{N} \sum_{t=1}^{T} x_{i t} \frac{\phi_{i t}}{1-\Phi_{i t}}=0 \\
\frac{\partial L L}{\partial \sigma^{2}} & =-\frac{N T}{2 \sigma^{2}}+\frac{1}{2 \sigma^{4}} \sum_{i=1}^{N} \sum_{t=1}^{T} \varepsilon_{i t}^{2}+\frac{\lambda}{2 \sigma^{3}} \sum_{i=1}^{N} \sum_{t=1}^{T} \varepsilon_{i t} \frac{\phi_{i t}}{1-\Phi_{i t}}=0, \\
\frac{\partial L L}{\partial \lambda} & =-\frac{1}{\sigma} \sum_{i=1}^{N} \sum_{t=1}^{T} \varepsilon_{i t} \frac{\phi_{i t}}{1-\Phi_{i t}}=0 \\
\frac{\partial L L}{\partial \delta} & =\frac{1}{\sigma^{2}} \sum_{i=1}^{N} \sum_{j=1}^{N} \sum_{t=1}^{T} \varepsilon_{i t} w_{i j} y_{j t}-T \frac{W}{I_{N}-\delta W}+\frac{\lambda}{\sigma} \sum_{i=1}^{N} \sum_{j=1}^{N} \sum_{t=1}^{T} w_{i j} y_{j t} \frac{\phi_{i t}}{1-\Phi_{i t}}=0,
\end{aligned}
$$

where $\Phi_{i t}=\Phi\left(\frac{\varepsilon_{i t} \lambda}{\sigma}\right), \phi_{i t}=\phi\left(\frac{\varepsilon_{i t} \lambda}{\sigma}\right), \Phi$ is as defined previously and $\phi$ is the associated probability density function.

There are a number of possible ways of implementing ML estimation of Eq. 1. The approach which we employ involves using a combination of ML estimation methods. We follow the approach in Fan et al. (1996). ${ }^{6}$ We first rewrite Eq. 1 as $y_{i t} \equiv E(y \mid \beta, \delta)+$ $\varrho\left(\lambda, \sigma^{2}\right)+\varepsilon_{i t}$, where $\varrho$ is a scalar and $\varrho\left(\lambda, \sigma^{2}\right)=(\sqrt{2} \sigma \lambda) /\left[\pi\left(1+\lambda^{2}\right)\right]^{1 / 2}$. Then using Eqs. 4 and 5 , the following expression for $\widehat{\sigma}^{2}$ can be derived, which is a consistent estimator

\footnotetext{
${ }^{6}$ Fan et al. (1996) use a semi-parametric approach to estimate a non-spatial stochastic frontier where, firstly, they use a kernel estimator to calculate an expected value of the dependent variable and secondly, they obtain efficiencies using parametric pseudo-likelihood estimation. Our approach involves using parametric estimation for both steps. The derivations presented in Fan et al. (1996) show that the loglikelihood can be expressed as a function of a single parameter $\lambda$ when it is assumed that the expected value of the dependent variable does not depend on $\lambda$.
} 
of $\sigma^{2}$ :

$$
\widehat{\sigma}^{2}=\frac{1}{N T} \sum_{i=1}^{N} \sum_{t=1}^{T}\left[y_{i t}-E(y \mid \beta, \delta)\right]^{2} /\left[1-2 \lambda^{2} / \pi\left(1+\lambda^{2}\right)\right] .
$$

We follow, among others, Elhorst (2009) for the SAR panel data model and obtain the conditional expectation $E(y \mid \beta, \delta)$ using the following concentrated log-likelihood function:

$$
L L_{C}=\Omega-\frac{N T}{2} \log \left[\left(e_{0}-\delta e_{1}\right)^{\prime}\left(e_{0}-\delta e_{1}\right)\right]+T \log \left|I_{N}-\delta W\right|,
$$

where $\Omega$ is a constant that does not depend on $\delta$, and $e_{0}$ and $e_{1}$ are the OLS residuals from successively regressing $y$ and $\left(I_{T} \otimes W\right) y$ on $X$. The concentrated log-likelihood function is obtained from the log-likelihood function in Eq. 2 but with the last term relating to the skewed error omitted. This log-likelihood function is concentrated with respect to the coefficient vector and the noise variance computed using the above OLS residuals $e_{0}$ and $e_{1}$. The concentrated log-likelihood function contains just one unknown parameter $\delta$, which has to be computed numerically as a closed form solution does not exist. The search procedure involves maximization of Eq. 8, where before commencing the iterative procedure we follow Pace and Barry (1997) for spatial non-frontier models and calculate $\log \left|I_{N}-\delta W\right|$ for a vector of values for $\delta$ over the interval $\left(\frac{1}{r_{\min }}, 1\right)$. As suggested by Pace and Barry (1997) we calculate $\log \left|I_{N}-\delta W\right|$ for values of $\delta$ based on 0.001 increments over the above feasible range for $\delta .^{7}$ The implicit solution for the ML estimate of $\beta$ is as follows using $\widehat{\delta}$ from the maximization of the concentrated log-likelihood function:

$$
\widehat{\beta}=\left(X^{\prime} X\right)^{-1} X^{\prime}\left[y-\delta\left(I_{T} \otimes W\right) y\right]
$$

where $I_{T}$ is the $(T \times T)$ identity matrix and $\otimes$ is the Kronecker product.

Following LeSage and Pace (2009) we obtain the standard errors using a mixed analytical-numerical Hessian, where all the second order derivatives are computed analytically, with the exception of $\partial^{2} L L / \partial \delta^{2}$ which is evaluated numerically. ${ }^{8}$ Evaluating

\footnotetext{
${ }^{7}$ As previously noted, we evaluate $\log \left|I_{N}-\delta W\right|$ using a vector of values for $\delta$, which LeSage and Pace (2009) refer to as the vectorized approach. Another approach to compute $\log \left|I_{N}-\delta W\right|$ which Ord (1975) proposed is $\left|I_{N}-\delta W\right|=\prod_{i}^{N}\left(1-\delta r_{i}\right)$, where $r_{i}$ is a root of $W$. With the vectorized approach, knowing only the largest and smallest real characteristic roots of $W, \log \left|I_{N}-\delta W\right|$ is evaluated for the vector of values of $\delta$ prior to the iterative procedure. The values of $\log \left|I_{N}-\delta W\right|$ are stored and then used in the iterative procedure. With the Ord approach $\log \left|I_{N}-\delta W\right|$ must be computed for each iteration. In addition, all the roots of $W$ are needed to calculate $\log \left|I_{N}-\delta W\right|$ with the Ord approach and for some asymmertric specifications of $W$ there is the added difficulty of calculating the complex roots of $W$. LeSage and Pace (2009) are therefore of the opinion that it is only feasible to compute all the roots of $W$ and thus use the Ord approach to evaluate $\log \left|I_{N}-\delta W\right|$ when $N$ is 'small or moderate'. Even though $N$ is quite small in the application (41) we still use the vectorized approach because this approach can also be used when $N$ is very large (e.g. $N>3,100$ for counties and county equivalents in continental United States).

${ }^{8}$ An alternative to the mixed analytical-numerical Hessian which we employ is a sandwich expression for the variance-covariance matrix. The advantage of a sandwich estimator is that it yields a consistent estimate of the variance-covariance matrix under misspecified variance-covariances and heteroskedastic errors. It is well-known, however, that, in general, a sandwich variance-covariance matrix yields a larger
} 
the second order derivatives of the log-likelihood function analytically rather than numerically is less sensitive to badly scaled data, and numerical rather than analytical evaluation of $\partial^{2} L L / \partial \delta^{2}$ when $N$ is very large avoids any difficulties (or lengthy computation time) associated with evaluating the dense spatial multiplier matrix, $\left(I_{N}-\delta W\right)^{-1} .^{9}$

Next we apply the pseudo-likelihood (PSL) method suggested by Fan et al. (1996) and maximize the following concentrated log-likelihood function $L L(\lambda)$ over the single parameter $\lambda$ :

$$
\begin{aligned}
L L(\lambda) & =-N T \ln \widehat{\sigma}+\sum_{i=1}^{N} \sum_{t=1}^{T} \ln \left[1-\Phi\left(\frac{\widehat{\varepsilon}_{i t} \lambda}{\sigma}\right)\right]-\frac{1}{2 \widehat{\sigma}^{2}} \sum_{i=1}^{N} \sum_{t=1}^{T} \widehat{\varepsilon}_{i t}^{2}, \\
\widehat{\varepsilon}_{i t} & =y_{i t}-E(y \mid \beta, \delta)-\varrho\left(\lambda, \sigma^{2}\right), \\
\widehat{\sigma} & =\left\{\frac{1}{N T} \sum_{i=1}^{N} \sum_{t=1}^{T}\left[y_{i t}-E(y \mid \beta, \delta)\right]^{2} /\left[1-2 \lambda^{2} / \pi\left(1+\lambda^{2}\right)\right]\right\}^{1 / 2} .
\end{aligned}
$$

The solution to $L L(\lambda)$ yields $\widehat{\lambda}$, the pseudo-likelihood estimate of $\lambda$. Substituting $\hat{\lambda}$ into Eq. 7 gives the pseudo-likelihood estimate of $\sigma^{2}$ which we denote $\widehat{\sigma}^{2}$ with slight abuse of notation. The consistent estimator of the constant term is scaled up by the value of $\widehat{\varrho}\left(\lambda, \sigma^{2}\right) \cdot{ }^{10}$

Having estimated $\beta, \delta, \lambda$ and $\sigma^{2}$ we compute the composed prediction error using Eq. 11. To estimate efficiency, $\xi_{i t}$, we use the following Jondrow et al. (1982) method to predict $u_{i t}$ conditional on $\varepsilon_{i t}$ :

$$
\widehat{u_{i t}}=E\left(u_{i t} \mid \varepsilon_{i t}\right)=\frac{\sigma_{u} \sigma_{v}}{\sigma}\left(\frac{\phi_{i t}}{1-\Phi_{i t}}-\frac{\varepsilon_{i t} \lambda}{\sigma}\right)
$$

where $\xi_{i t}=\exp \left(-\widehat{u_{i t}}\right)$. Finally, for SAR stochastic cost and output distance frontiers, the log-likelihood function and the estimation procedure are the same as above but with $\frac{\varepsilon_{i t} \lambda}{\sigma}$ replaced by $-\frac{\varepsilon_{i t} \lambda}{\sigma}$ in $\Phi_{i t}$ and $\phi_{i t}, \frac{\phi_{i t}}{1-\Phi_{i t}}$ replaced by $-\frac{\phi_{i t}}{1-\Phi_{i t}}$ and $\xi_{i t}=\exp \left(\widehat{u_{i t}}\right)$.

The above estimation procedure for the SAR stochastic frontier comprises, among other things, a consistent estimator of $\xi$ which is potentially more efficient than other estimators of $\xi$ that we could have employed such as the method of moments estimator. In the application, the estimation procedure appears to perform well as the two specifications of the SAR stochastic frontier which we estimate both converge and yield direct marginal

variance than classical estimators of the variance-covariance matrix (Kauermann and Carroll, 2001). Various methods have been used in the stochastic frontier literature to estimate the variance-covariance matrix. Our approach can be viewed as an adaptation to the spatial case of the information matrix used by ALS.

${ }^{9}$ Even though $N$ is quite small in the application section, we compute $\partial^{2} L L / \partial \delta^{2}$ numerically rather than analytically as this approach can also be used to compute $\partial^{2} L L / \partial \delta^{2}$ when $N$ is very large. We calculate $\partial^{2} L L / \partial \delta^{2}$ numerically as follows: $\frac{\partial^{2} L L}{\partial \delta^{2}}=\frac{\partial^{2} L L_{C}}{\partial \delta^{2}}+\frac{\partial^{2} L L}{\partial \delta \partial \varsigma^{\prime}}\left(\frac{\partial^{2} L L}{\partial \varsigma \partial \varsigma^{\prime}}\right)^{-1} \frac{\partial^{2} L L}{\partial \varsigma \partial \delta}$, where $\varsigma$ is a vector of the coefficients and the noise variance.

${ }^{10}$ For SAR stochastic cost and output distance frontiers the constant term is scaled down by $\widehat{\varrho}\left(\lambda, \sigma^{2}\right)$. 
effects for the key variables which are in line with estimates in the relevant literature. Moreover, from both specifications of the SAR stochastic frontier we obtain a plausible set of efficiencies. A Monte Carlo analysis is an area for further work which would provide a comprehensive assessment of the statistical performance of, among other things, the efficiency estimator. ${ }^{11}$

\section{Direct, Indirect and Total Relative Efficiencies}

LeSage and Pace (2009) demonstrate that for models such as Eq. 1 the coefficients on the independent variables cannot be interpreted as elasticities. This is because the marginal effect of an independent variable is a function of the SAR variable. To address this issue they propose disentangling the effect of an independent variable from the effect of the SAR variable by using the fitted parameters to calculate direct, indirect and total marginal effects. This approach involves using the reduced form of Eq. 1:

$$
y_{t}=\left(I_{N}-\delta W\right)^{-1} X_{t} \beta+\left(I_{N}-\delta W\right)^{-1} v_{t}-\left(I_{N}-\delta W\right)^{-1} u_{t},
$$

where the $i$ subscripts are dropped to denote successive stacking of cross-sections, $X_{t}$ is an $(N \times K)$ matrix of stacked observations for $x_{i t}$ and all the other variables and parameters are as above. For details on what is now a standard approach in spatial econometrics to calculate the direct, indirect and total marginal effects by differentiating Eq. 14 see LeSage and Pace (2009) and Elhorst (2014). We note, however, rather than follow their approach to calculate the $t$-statistics for the direct, indirect and total marginal effects via Bayesian MCMC simulation of the distributions of the marginal effects we calculate the $t$-statistics for the marginal effects using the delta method.

It is interesting to note at this juncture the relationship between spatial models such as Eq. 1 and the well-established literature on simultaneous equation models. The origins of spatial models can be traced to the literature on systems of simultaneous equations because spatial models are a particular type of simultaneous equation model. This is because there is a bidirectional relationship in a spatial model between the dependent variable and the SAR variable or the spatial autocorrelated error term. Hence the endogeneity of the SAR variable and the spatial autocorrelated error term. A unit in a spatial model is therefore simultaneously exporting and importing spillovers to and from its neighbors. The indirect marginal effects from a spatial model measure the magnitude of the spillovers which are imported and exported in the sample. As we noted above for a model which takes the form of Eq. 1, there are two valid ways of calculating an average indirect marginal effect which yield the same numerical value. This leads to

\footnotetext{
${ }^{11}$ Accounting for incorrect skewness in the SAR stochastic frontier model is another area for further work. See Almanidis and Sickles (2012) and Almanidis, Qian and Sickles (2014) on how to address incorrect skewness in the non-spatial stochastic frontier model in cross-sectional and panel data settings.
} 
two interpretations of an indirect marginal effect. The first interpretation relates to the magnitude of spillovers which are exported by a unit and is the average change in the dependent variable of all the other units following a change in an independent variable for one particular unit. The second interpretation relates to the magnitude of spillovers which are imported by a unit and is the average change in the dependent variable for a particular unit following a change in an independent variable for all the other units.

By adapting the approach to estimate the marginal effects we compute the timevaryng estimates of the relative direct, relative indirect and relative total efficiencies. This involves recognizing that $-\left(I_{N}-\delta W\right)^{-1} u_{t}=-u_{t}^{T o t}$, where $-u_{t}^{T o t}$ is the $(N \times 1)$ vector of total inefficiencies. It follows that $\left(I_{N}-\delta W\right)^{-1} \exp \left(-u_{t}\right)=\xi_{t}^{T o t}$, where $\xi_{t}^{T o t}$ is the $(N \times 1)$ vector of total efficiencies. Thus we can write:

$$
\left(I_{N}-\delta W\right)^{-1}\left(\begin{array}{c}
\xi_{1} \\
\xi_{2} \\
\cdot \\
\cdot \\
\xi_{N}
\end{array}\right)=\left(\begin{array}{cccccccc}
\xi_{11}^{D i r} & + & \xi_{12}^{I n d} & + & \cdot & \cdot & + & \xi_{1 N}^{I n d} \\
\xi_{21}^{I n d} & + & \xi_{22}^{\text {Dir }} & + & \cdot & \cdot & + & \xi_{2 N}^{I n d} \\
\cdot & + & \cdot & + & \cdot & \cdot & + & \cdot \\
\cdot & + & \cdot & + & \cdot & + & \cdot \\
\xi_{N 1}^{I n d} & + & \xi_{N 2}^{I n d} & + & \cdot & \cdot & + & \xi_{N N}^{D i r}
\end{array}\right)=\left(\begin{array}{c}
\xi_{1}^{T o t} \\
\xi_{2}^{T o t} \\
\cdot \\
\cdot \\
\xi_{N}^{T o t}
\end{array}\right)
$$

where $\xi_{i j}^{D i r}(i=j)$ and $\xi_{i j}^{I n d}(i \neq j)$ are direct and indirect efficiencies. By making an assumption about the distribution of $u_{t}$, as we have done here, the benchmarking exercise yields $\xi_{t}$, which is relative to an absolute best practice frontier. $\xi^{D i r}, \xi^{I n d}$ and $\xi^{T o t}$, however, are not relative to absolute best practice frontiers. To aid the interpretation of $\xi^{D i r}, \xi^{I n d}$ and $\xi^{\text {Tot }}$ we adapt the SS method and apply it to $\xi^{D i r}$, $\xi^{\text {Ind }}$ and $\xi^{\text {Tot }}$ to obtain time-varying estimates of the relative direct, relative indirect and relative total efficiencies. The relative direct, relative indirect and relative total efficiencies are relative to the best performing unit in the sample in each time period and are calculated as follows.

$$
\begin{gathered}
R E_{i t}^{D i r}=\frac{\xi_{i j t}^{D i r}}{\max _{i}\left(\xi_{i j t}^{\text {Dir }}\right)}=R E_{j t}^{\text {Dir }}=\frac{\xi_{i j t}^{\text {Dir }}}{\max _{j}\left(\xi_{i j t}^{\text {Dir }}\right)}, \\
R E_{i t}^{\text {Ind }}=\frac{\sum_{j=1}^{N} \xi_{i j t}^{\text {Ind }}}{\max _{i}\left(\sum_{j=1}^{N} \xi_{i j t}^{\text {Ind }}\right)}, \\
R E_{j t}^{I n d}=\frac{\sum_{i=1}^{N} \xi_{i j t}^{I n d}}{\max _{j}\left(\sum_{i=1}^{N} \xi_{i j t}^{I n d}\right)},
\end{gathered}
$$




$$
\begin{aligned}
& R E_{i t}^{T o t}= \frac{\xi_{i j t}^{\text {Dir }}+\sum_{j=1}^{N} \xi_{i j t}^{I n d}}{\max _{i}\left(\xi_{i j t}^{D i r}+\sum_{j=1}^{N} \xi_{i j t}^{I n d}\right)}, \\
& R E_{j t}^{T o t}=\frac{\xi_{i j t}^{\text {Dir }}+\sum_{i=1}^{N} \xi_{i j t}^{I n d}}{\max _{j}\left(\xi_{i j t}^{\text {Dir }}+\sum_{i=1}^{N} \xi_{i j t}^{I n d}\right)} .
\end{aligned}
$$

$R E_{i t}^{I n d}$ refers to efficiency spillovers to the $i t h$ unit from all the $j t h$ units. It is also valid to interpret relative indirect efficiency as $R E_{j t}^{I n d}$, which refers to efficiency spillovers to all the $i t h$ units from a particular $j t h$ unit. Since $\xi_{i j t}^{I n d} \neq \xi_{j i t}^{I n d}, R E_{i t}^{I n d} \neq R E_{j t}^{I n d}$ so there are asymmetric directional efficiency spillovers. Hence $R E_{i t}^{T o t} \neq R E_{j t}^{T o t}$. We calculate $R E_{i t}^{D i r}$ and $R E_{i t}^{I n d}$ as shares of $R E_{i t}^{T o t}$, which we denote $S R E_{i t}^{D i r}$ and $S R E_{i t}^{I n d}$. We also calculate $R E_{j t}^{D i r}$ and $R E_{j t}^{I n d}$ as shares of $R E_{j t}^{T o t}$, which we denote $S R E_{j t}^{D i r}$ and $S R E_{j t}^{I n d}$. To estimate $S R E_{i t}^{D i r}$ and $S R E_{i t}^{I n d}$ we calculate $R E_{i t}^{D i r}, R E_{i t}^{I n d}$ and $R E_{i t}^{T o t}$ relative to the same unit, where this unit is the best performing unit in the calculation of $R E_{i t}^{T o t}$. Along the same lines, to estimate $S R E_{j t}^{D i r}$ and $S R E_{j t}^{I n d}$ we calculate $R E_{j t}^{D i r}, R E_{j t}^{I n d}$ and $R E_{j t}^{T o t}$ relative to the best performing unit in the calculation of $R E_{j t}^{T o t}$. Formally we recognize that $R E_{i t}^{T o t}$ and $R E_{j t}^{T o t}$ can be disaggregated into relative direct and relative indirect efficiency components as follows:

$$
\begin{aligned}
& R E_{i t}^{T o t}=\frac{\xi_{i j t}^{\text {Dir }}}{\max _{i} E_{i t}^{T o t}\left(\xi_{i j t}^{\text {Dir }}\right)}+\frac{\sum_{i=1}^{N} \xi_{i j t}^{\text {Ind }}}{\max _{i} E_{i t}^{T o t}\left(\sum_{j=1}^{N} \xi_{i j t}^{I n d}\right)}, \\
& R E_{j t}^{T o t}=\frac{\xi_{i j t}^{\text {Dir }}}{\max _{R E_{j t}^{T o t}}\left(\xi_{i j t}^{\text {Dir }}\right)}+\frac{\sum_{j=1}^{N} \xi_{i j t}^{I n d}}{\max _{R E_{j t}^{T o t}}\left(\sum_{i=1}^{N} \xi_{i j t}^{I n d}\right)} .
\end{aligned}
$$

It is possible for either term in Eq. 21 or Eq. 22 to be greater than 1 if the unit with the highest total efficiency is not also the unit with the highest direct efficiency and/or the highest indirect efficiencies. If this were the case it would indicate that there are units that operate beyond the direct and/or indirect reference levels in Eq. 21 and/or Eq. $22 .{ }^{12}$ $S R E_{i t}^{D i r}$ is the first term on the right-hand side of Eq. 21 as a share of $R E_{i t}^{T o t} . S R E_{i t}^{I n d}$, $S R E_{j t}^{D i r}$ and $S R E_{j t}^{I n d}$ are calculated in the same manner.

\footnotetext{
${ }^{12}$ As we noted above, in the application we estimate two specifications of the SAR frontier in Eq. 1. From both specifications there are no cases in the application where a term from Eq. 21 or Eq. 22 is greater than 1.
} 


\section{Application to Aggregate Production in Europe}

As is standard in applied spatial econometrics we use panel data which is balanced. ${ }^{13}$ Using aggregate data for 41 European countries for the period 1990 - 2011, which we describe in subsection 4.1, we estimate SAR and spatial Durbin stochastic production frontiers (denoted SARF and SDF, respectively, from hereon). Both the SARF which we estimate and the SDF are different specifications of a general class of SARF models as represented by Eq. 1. We also estimate the corresponding local spatial and non-spatial stochastic production frontiers (denoted LSF and NSF, respectively, from hereon), where the LSF is the SDF with the SAR term omitted. The LSF therefore only accounts for 1st order spatial interaction via the spatial lags of the exogenous variables (e.g. a first order Germany-France spatial effect is the effect of Germany's capital on France's output). The LSF does not account for global spatial interaction (1st order through to $(N-1)$ th order spatial interaction where a second order Germany-France spatial effect would be, for example, the effect of Germany's output on the Netherlands' output which in turn via the spatial multiplier matrix affects France's output). The SARF and the SDF, on the other hand, account for global spatial interaction via the SAR variable. The LSF can therefore be estimated using the standard procedure which we use to estimate the NSF.

We use the production technology which underlies the Solow $(1956 ; 1957)$ neoclassical growth model and employ a Cobb-Douglas specification. The specification of the SDF is very similar to the specification of the spatial Durbin production function in Koch (2008). That said, in Koch's specification spatial lags of the exogenous inputs shift the technology, whereas in our SDF a number of additional variables also shift the technology. ${ }^{14}$ Since the SDF nests the NSF, SARF and LSF we can present the models which we estimate in this application section using only the following SDF, where lower case letters denote logged variables unless otherwise stated in the discussion of the data in subsection 4.1:

$$
\begin{aligned}
y_{i t}= & \kappa+\eta_{1} t+\eta_{2} t^{2}+g_{i t} \varpi+z_{i t} \psi+\sum_{j=1}^{N} w_{i j} g_{j t} \zeta+\sum_{j=1}^{N} w_{i j} h_{j t} \theta+ \\
& \delta \sum_{j=1}^{N} w_{i j} y_{j t}+v_{i t}-u_{i t} .
\end{aligned}
$$

$y_{i t}$ is output of the $i t h$ country at time $t$ and $g_{i t}$ is a vector of inputs. The remaining

\footnotetext{
${ }^{13}$ The asymptotic properties of spatial estimators (e.g. spatial error and SAR non-frontier models, as well as the SAR stochastic frontier estimator which we develop here) become problematic for unbalanced panels if the reason why data are missing is not known (Elhorst, 2009). Extending such estimators to an unbalanced panel data setting therefore involves making an assumption about why observations are missing. For example, Pfaffermayr (2013) assumes that data are missing at random for an unbalanced spatial panel.

${ }^{14}$ See the unrestricted regression results in Table 2 of Koch (2008).
} 
variables in Eq. 23 shift the frontier technology and are as follows: $t$ is a time trend, where $t$ and $t^{2}$ are included to account for Hicks-neutral technological change, $\sum_{j=1}^{N} w_{i j} g_{j t}$ is a vector of spatial lags of the inputs, $z_{i t}$ is a vector of non-spatial variables, $\sum_{j=1}^{N} w_{i j} h_{j t}$ is a vector of spatial lags of a subset of elements of $z_{i t}$ and $\sum_{j=1}^{N} w_{i j} y_{j t}$ is as defined for Eq. 1. $\kappa$ is the intercept and $\eta_{1}, \eta_{2} \varpi, \psi, \zeta, \theta$ and $\delta$ are parameters or vectors of parameters. Turning now to a more detailed discussion of the variables.

\subsection{Variables, Data and the Spatial Weights Matrix}

All the data was extracted from version 8.0 of the Penn World Table, PWT8.0 (Feenstra et al., 2013a), which is first version of the Penn World Table to include estimated data for capital stock. Output is output-side real GDP, y (in 2005 million U.S. dollars at 2005 PPPs, rgdpo), where PWT8.0 notation for the variables is given in parentheses. As recommended in the documentation which accompanies PWT8.0 we use rgdpo to analyze productivity across countries rather expenditure-side real GDP (rgdpe) or GDP at 2005 national prices (rgdpna) (see page 31 in Feenstra et al., 2013b). $g$ is a $(1 \times 2)$ vector of input levels. The first input is the labor input and is the number of people engaged, $g_{1}$ $(e m p)$. Real capital stock at current PPPs is the second input, $g_{2}$ (in 2005 million U.S. dollars, $c k) .{ }^{15}$

The spatial lags of the inputs in Eq. 23 are denoted as $\left(I_{T} \otimes W\right) g_{1}$ and $\left(I_{T} \otimes W\right) g_{2}$ in the presentation of the fitted models. $z$ is a $(1 \times 3)$ vector of variables, where $z_{1}$ measures net trade openness and is net exports of merchandise as a share of GDP $\left(z_{1}=\right.$ $c s h \_x+c s h \_m$ because all the observations for $c s h \_m$ in PWT8.0 are negative to signify that imports are a leakage). $z_{2}$ is government spending as a share of GDP (csh_g) and $z_{3}$ is a dummy variable for EU membership. $\left(I_{T} \otimes W\right) h$ is a $(1 \times 2)$ vector of spatial lags of $z_{1}$ and $z_{2}$ denoted $\left(I_{T} \otimes W\right) z_{1}$ and $\left(I_{T} \otimes W\right) z_{2}$, respectively. ${ }^{16}$ All the continuous variables which are not shares are logged. The descriptive statistics for the continuous variables are presented in Table 1 and are for the raw data.

\section{[Insert Table 1]}

In summary, the difference between the SARF, SDF, LSF and NSF models relates to the variables which shift the frontier technology. For the NSF only $t, t^{2}$ and $z$ shift the frontier technology compared to $t, t^{2}, z,\left(I_{T} \otimes W\right) g$ and $\left(I_{T} \otimes W\right) h$ for the LSF, $t$, $t^{2}, z$ and $\left(I_{T} \otimes W\right) y$ for the SARF, and $t, t^{2}, z,\left(I_{T} \otimes W\right) g,\left(I_{T} \otimes W\right) h$ and $\left(I_{T} \otimes W\right) y$ for the SDF. As is evident from Eq. 23, we do not capture unobserved time-invariant

\footnotetext{
${ }^{15}$ Following the documentation which accompanies PWT8.0 (see page 13 in Inklaar and Timmer, 2013) we use $c k$ as our measure of real capital stock rather than real capital stock at 2005 national prices (in 2005 million U.S. dollars, rkna).

${ }^{16}$ There are no spatial lags of $t, t^{2}$ and $z_{3}$ in the specifications of the LSF and the SDF. In all three cases this is for reasons of perfect collinearity, e.g. $\left(I_{T} \otimes W\right) t=t$.
} 
heterogeneity via fixed or random effects. See Chen et al. (2014) for a non-spatial stochastic frontier model with consistent estimates of the fixed effects, and Greene (2005) for a non-spatial stochastic frontier model with random effects. ${ }^{17}$ We do, however, account for spatial heterogeneity via the SAR variable in the SARF and the SDF. This is because $\delta$ measures the degree of spatial dependence of $y$ in the cross-sections. Assuming $\delta$ is positive, which is usually the case, a high degree of spatial heterogeneity in the sample will not only have implications for the significance of $\delta$ but it will also have a downward effect on the magnitude of $\delta .{ }^{18}$ Along similar lines, Zimmerman and Harville (1991) argue that the spatial error term "soaks up" spatial heterogeneity, but for reasons given above we have a strong preference for the general class of SARF models (which includes the SDF) over a spatial error specification.

In the application we use a single row-normalized inverse distance specification of $W .{ }^{19}$ The specification of $W$ is symmetric and dense as the spatial weights are the row-normalized inverse distances between each pair of capital cities. ${ }^{20}$ Such a dense specification of $W$ is appealing as it captures the spatial interaction between every pair of countries and does not therefore involve using an arbitrary cut-off for the number of neighbors (e.g.. the three, four or five nearest neighbors). Using a row-normalized $W$ also simplifies the calculation of the limits of the values of $\delta$ used to evaluate $\log \left|I_{N}-\delta W\right|{ }^{21}$ Since we know the largest real characteristic root of a row-normalized $W$ is 1 , we only need to find the most negative real characteristic root of $W$. In addition, since the specification of $W$ which we use in the application is an inverse distance matrix, the spatial weights are exogenous. Finally, we note that even though the specification of $W$ which we use is dense, inverting $\left(I_{N}-\delta W\right)$ in the estimation posed no problems.

\subsection{Fitted Models}

In this subsection we present and analyze the fitted NSF, LSF, SARF and SDF models. Moreover, we use the fitted models to make a case for the SDF. In Table 2 we present

\footnotetext{
${ }^{17}$ A logical extension of Eq. 1 is to control for unobserved heterogeneity using fixed or random effects. Another approach may entail the development of alternative ways to control for unobserved heterogeneity and common shocks in spatial stochastic frontier models, possibly building on the factor model approach of Kniep, Sickles and Song (2012).

${ }^{18} \mathrm{Kao}$ and Bera (2013) consider what they describe as the 'curious case' of negative spatial dependence, whilst acknowledging that positive spatial dependence dominates in spatial data and therefore also dominates in the spatial literature on estimation, testing and forecasting.

${ }^{19}$ As we noted in subsection 2.1, the specification of $W$ is row-normalized so the SAR variable is a weighted average of observations for the dependent variable for neighboring units which facilitates interpretation. Specifically, spillovers are therefore inversely related to the relative (and not the absolute) great circle distance between units.

${ }^{20}$ Since the specification of $W$ which we use is symmetric all its roots are real. In general, asymmetric specifications of $W$ have complex roots but row-normalizing such matrices yields specifications of $W$ which have only real roots.

${ }^{21}$ As we previously noted, the limits of $\delta$ are taken to be $\left(\frac{1}{r_{\min }}, \frac{1}{r_{\max }}\right)$, where $r_{\min }$ is the most negative real characteristic root of $W$ and $r_{\max }$ is the largest real characteristic root of $W$.
} 
the fitted SDF which is our preferred specification which we provide a justification for shortly. To enable comparisons with our preferred SDF in Table 2 we also present the NSF and the corresponding LSF and SARF models. Like the SARF and SDF models, the NSF and LSF models have a normal half-normal disturbance structure so there is a direct correspondence between the four model specifications. In Table 3 we present the direct, indirect and total marginal effects for the SARF and SDF models.

\section{[Insert Tables 2 and 3]}

The estimates of $\delta$ in Table 2 are not spillover elasticities. The spillover elasticities from the SARF and SDF models are the indirect marginal effects which are a function of, among other things, $\delta$ (see LeSage and Pace, 2009, and Elhorst, 2014). The estimates of $\delta$, however, indicate how the spatial dependence of $y$ is affected by the model specification. It is evident from Table 2 that for the SARF and SDF models, the estimates of $\delta$ are significant at the $5 \%$ level or lower. The estimates of $\delta$ from the SARF and SDF models are also of a similar order of magnitude, which suggests that the degree of global spatial dependence is robust to model specification.

To choose between the fitted NSF, LSF, SARF and SDF models, we use the approach which Pfaffermayr (2009) uses to choose between different specifications of the spatial weights matrix for a SAR non-frontier model and base our model selection on the Akaike Information Criteria (AIC). To check the robustness of the model selection using the AIC we also use the Schwarz/Bayesian Information Criteria (BIC). It is apparent from Table 2 that we have a strong preference for the SDF over the NSF, LSF and SARF models as the SDF yields the lowest AIC and BIC values. We can also see from Table 2 that all the local spatial parameters from the fitted LSF and SDF models $\left(\zeta_{1}, \zeta_{2}, \theta_{1}\right.$ and $\left.\theta_{2}\right)$ are significant at the $1 \%$ level or lower. Interestingly, however, we find that the AIC and BIC clearly favor the LSF over the SARF and marginally favor the NSF over the SARF.

The remainder of the discussion in this subsection tends to focus on the marginal effects from the preferred SDF model. From Table 2 we can see that the own labor (capital) elasticities from the NSF and the LSF are of the order 0.289 (0.668) and 0.320 (0.633), respectively. Table 3 reveals that the direct labor (capital) elasticities from the SARF and the SDF models are 0.286 (0.681) and 0.300 (0.652), respectively. All the own/direct labor and capital parameters from the NSF, LSF, SARF and SDF models have the expected positive signs and are significant at the $1 \%$ level or lower. To be in line with convention, however, the own/direct labor elasticity should be about $\frac{2}{3}$ and the own/direct capital elasticity should be around $\frac{1}{3}$. Our results point more towards own/direct labor and capital elasticities which are of the opposite order of magnitude. In particular, we report own/direct labor elasticities which are much closer to $\frac{1}{3}$ than $\frac{2}{3}$, and own/direct capital elasticities which are approximately $\frac{2}{3}$. Using data for 91 non-oil 
countries for 1995 from version 6.1 of the Penn World Table, Koch (2008) estimates nonspatial and spatial specifications of the Cobb-Douglas production function and reports own labor elasticities of the order $0.268-0.310$ and own capital elasticities ranging from $0.679-0.718$, thus providing support for our estimates of the own/direct input elasticities. $^{22}$

Romer (1987) argues that conventional growth accounting where the own labor elasticity is around $\frac{2}{3}$ and the own capital elasticity is about $\frac{1}{3}$ substantially underestimates the role of capital accumulation in growth. He is instead in agreement with our estimates of the own/direct input elasticities (and the above estimates reported by Koch (2008)), arguing that innovation from capital accumulation is sensitive to wages so when wages are relatively high, as is the case in many European countries, innovative investment economizes on labor pushing the own/direct labor elasticity substantially down and the own/direct capital elasticity substantially up.

We find that the direct net trade openness $\left(z_{1}\right)$ and direct EU membership $\left(z_{3}\right)$ parameters from the SDF model have the expected positive signs and are both significant at the $0.1 \%$ level. Also, the direct government size $\left(z_{2}\right)$ parameter from the SDF model has the expected negative sign and is significant at the $0.1 \%$ level, which is consistent with the significant negative relationship which Főlster and Henrekson (2001) observe between government size and economic growth from a non-spatial non-frontier model. With regard to the indirect input elasticities from the SDF model, the picture is similar to what we observed for the corresponding direct input elasticities. This is apparent because the indirect labor and indirect capital elasticities are both positive and significant at the $1 \%$ level or lower, and the indirect labor elasticity (0.076) is smaller in magnitude than the indirect capital elasticity (0.166). It is therefore evident that the indirect labor and indirect capital elasticities from the SDF model are smaller than the associated direct elasticity.

The SDF model yields indirect $z_{1}-z_{3}$ parameters which have the same sign as the corresponding direct effect but only the indirect $z_{1}$ and $z_{2}$ parameters are significant. Moreover, the indirect $z_{1}$ and $z_{2}$ parameters from the SDF model are much smaller in magnitude than the corresponding direct elasticity. Finally, we note that the direct time parameter from the SDF model is negative and significant at the $0.1 \%$ level. This is consistent with the time parameter from Kumbhakar and Wang's (2005) non-spatial stochastic production frontier analysis of 87 countries, and also the time parameters for various country groupings in recent studies of world productivity growth (Sickles et al., 2015; Duygun et al., 2015). We do not interpret the negative direct time effect from the SDF model as evidence of technological regress. Instead the interpretation is in the

\footnotetext{
${ }^{22}$ Koch (2008) estimates a spatial Durbin Cobb-Douglas production function but he does not proceed to calculate the required direct marginal effects, among other things. The valid ranges for the own labor and own capital elasticities from Koch (2008) which we report are therefore from the fitted non-spatial and spatial error Cobb-Douglas production functions.
} 
context of the application and we posit that the negative direct time effect is due to our sample consisting of a large number of Eastern European countries that underwent major reform during the study period.

\subsection{Technical Efficiency and Direct, Indirect and Total Relative Technical Efficiencies}

The average technical efficiencies from the NSF, LSF, SARF and SDF models are 0.773, $0.804,0.775$ and 0.792 , respectively. This suggests that average technical efficiency is robust to model specification. We find a high correlation between the average technical efficiencies of the countries and the average technical efficiency rankings for the countries from the NSF, LSF, SARF and SDF. This is evident because the lowest correlation between two sets of average technical efficiencies for the countries from the NSF, LSF, $\mathrm{SARF}$ and SDF is 0.913 . The lowest Spearman rank correlation between two sets of average efficiency rankings for the countries from the NSF, LSF, SARF and SDF is 0.863. Furthermore, it is evident from the kernel density plots in Figure 1 that the distributions of the four sets of technical efficiencies are similar. ${ }^{23}$ In all four cases the technical efficiency distribution is negatively skewed.

\section{[Insert Figure 1]}

In Table 4 we present for selected countries the average technical efficiencies and the corresponding average efficiency rankings from the NSF, LSF, SARF and SDF. It is evident that the average efficiency rankings for nearly all of the 14 countries in Table 4 are robust across the NSF, LSF, SARF and SDF models. ${ }^{24}$ To illustrate, in Table 4 there are countries with consistently low average efficiency rankings (Albania, Armenia, Belarus, Moldova and Ukraine), consistently high average efficiency rankings (Norway, UK and Sweden) and consistently mid-ranging efficiency rankings (Czech Republic and Slovenia). In addition, it is evident from Table 4 that although some countries have consistently low average efficiency rankings, when we control for local spatial dependence (LSF model) and/or SAR dependence (SARF and SDF models) absolute average efficiency for these countries is sometimes quite a lot higher than we observe from the NSF. This we suggest is because the LSF, SARF and SDF account for the geographical correlation of the independent variables and/or the dependent variable, which adjusts for the disadvantageous location of countries such as Albania, Armenia, Belarus, Moldova and Ukraine.

[Insert Table 4]

\footnotetext{
${ }^{23}$ To plot the kernel densities we use the Gaussian density and obtain the bandwidth using the Sheather and Jones (1991) solve-the-equation plug-in method.

${ }^{24}$ Cyprus is, for example, an exception with an average efficiency ranking of 32, 17, 31 and 16 from the NSF, LSF, SARF and SDF, respectively.
} 
The most interesting feature of the efficiency results in this application is the rich additional information about efficiency which can be obtained from the SARF and SDF models. This is because the SARF and SDF models yield estimates of direct, indirect and total relative technical efficiencies. In Table 5 for selected countries we present from the fitted SARF and SDF models the average relative efficiencies, and the average direct and average indirect relative efficiency shares. Specifically, the first row of results refers to estimates of $R E_{i t}^{D i r}, R E_{i t}^{I n d}$ and $R E_{i t}^{T o t}$ (Eqs. 16, 17 and 19) and the second row consists of estimates of $R E_{j t}^{\text {Dir }}, R E_{j t}^{I n d}$ and $R E_{j t}^{\text {Tot }}$ (Eqs. 16, 18 and 20). Using Eq. 21 we calculate the estimates of $R E_{i t}^{D i r}$ and $R E_{i t}^{I n d}$ in the third row, which are then used to calculate $S R E_{i t}^{\text {Dir }}$ and $S R E_{i t}^{I n d}$ in the fourth row. Similarly, using Eq. 22 we compute the estimates of $R E_{j t}^{D i r}$ and $R E_{j t}^{I n d}$ in the fifth row, which are then used to compute $S R E_{j t}^{D i r}$ and $S R E_{j t}^{I n d}$ in the sixth row.

\section{[Insert Table 5]}

The average estimates of $R E_{i t}^{\text {Dir }}$ from the SARF and the SDF are 0.865 and 0.840 , respectively. Interestingly, the average estimate of $R E_{i t}^{I n d}$ from the SARF is 0.981 , whereas the SARF yields an average estimate of $R E_{j t}^{I n d}$ of 0.638. Similarly, from the SDF the average estimate of $R E_{i t}^{I n d}$ is 0.974 , which far exceeds the average estimate of $R E_{j t}^{I n d}$ from the SDF (0.635). The estimates of $R E_{i t}^{I n d}$ (and the estimates of $R E_{j t}^{I n d}$ ) from the SARF and the SDF are similar because we use the same specification of $W$ for both models and obtain similar estimates of $\delta$. These estimates of average $R E_{i t}^{I n d}$ and average $R E_{j t}^{I n d}$ indicate strongly that countries are much more proficient at importing efficiency than they are at exporting efficiency. Furthermore, across the countries we observe a much wider range of estimates for average $R E_{j t}^{I n d}$ than we observe for average $R E_{i t}^{I n d}$. The range of average $R E_{j t}^{I n d}$ from the SARF and the SDF is the same $(0.25-1.00)$. In contrast, average $R E_{i t}^{I n d}$ from the SARF is of the order $0.965-0.991$ and the SDF yields average $R E_{i t}^{\text {Ind }}$ ranging from $0.955-0.985$.

The average estimates of $S R E_{i t}^{\text {Dir }}$ from the SARF and the SDF are 0.783 and 0.795, respectively. Average $S R E_{j t}^{\text {Dir }}$ from the SARF and the SDF are essentially of the same order of magnitude as the corresponding $S R E_{i t}^{D i r}$. As we would expect, this indicates that, on average, relative direct efficiency is by far the biggest component of relative total efficiency. This is also the case from the SARF and the SDF for all the countries in Table 5. This is the reason why from the SDF for countries such as Norway and the UK in Table 5, a relatively high $R E_{j t}^{D i r}$ outweighs a relatively low $R E_{j t}^{I n d}$, which results in a relatively high $R E_{j t}^{T o t}$ (see the second row of the SDF results for these two countries in Table 5). 


\section{Concluding Remarks}

By blending seminal literature on modeling stochastic frontiers with key contributions to spatial econometrics, our paper develops a SAR stochastic frontier model for panel data. Inefficiency varies over time and across the cross-sections and, as is common in the efficiency literature, inefficiency is distributed as half-normal. The SAR stochastic frontier is estimated using ML methods, where unlike the corresponding non-spatial frontier, with the SAR frontier there is an endogeneity issue pertaining to the SAR variable. In the estimation procedure which we develop we account for this endogeneity in the specification of the log-likelihood function.

Along the lines of the approach to calculate the direct, indirect and total marginal effects, we adapt the classic Schmidt and Sickles (1984) efficiency estimator to obtain time-varying estimates of direct, asymmetric indirect and asymmetric total efficiencies relative to the best performing unit in the sample in each time period. These relative efficiency scores can be very informative because in the application to aggregate production of European countries we find that average efficiency spillovers to a country are much larger than average efficiency spillovers from a country. This indicates that, on average, countries are more adept at importing efficiency than they are at exporting efficiency. This finding is consistent with the diffusion of knowledge embodied in imports of hi-tech goods and services from a relatively small number of technological leaders in the sample (e.g. Germany).

Since to the best of our knowledge our paper is the first to introduce a stochastic frontier model which models global spatial dependence and where an assumption is made about the inefficiency distribution, there are a number of possible extensions. Rather than assume that the inefficiency distribution is half-normal, one could apply a range of specifications of the non-spatial stochastic frontier to the spatial case and assume, for example, that inefficiency follows a truncated normal distribution (e.g. Stevenson, 1980) or a Gamma distribution (e.g. Greene, 1990), or alternatively, the inefficiency distribution could be specified using Bayesian methods (Liu, Sickles and Tsionas, 2015).

\section{Acknowledgments}

The authors acknowledge the constructive comments on an earlier version of this paper from two anonymous referees, the Guest Editor, Peter Schmidt, and Tom Weyman-Jones. Any remaining errors are the responsibility of the authors.

\section{References}

Adetutu, M., A. J. Glass, K. Kenjegalieva and R. C. Sickles (2014): 'The effects of efficiency and TFP growth on pollution in Europe: A multistage spatial analysis'. Forthcoming in the 
Journal of Productivity Analysis.

Aigner, D., C. A. K. Lovell and P. Schmidt (1977): 'Formulation and estimation of stochastic frontier production function models'. Journal of Econometrics, vol. 6, pp. 21-37.

Almanidis, P. And R. C. Sickles (2012): The skewness issue in stochastic frontier models: Fact or fiction? In Exploring Research Frontiers in Contemporary Statistics and Econometrics: A Festschrift in Honor of Léopold Simar, Van Keilegom, I., and P. W. Wilson (Eds). New York: Springer.

Almanidis, P., J. Qian And R. C. Sickles (2014): Stochastic frontiers with bounded inefficiency. In Festschrift in Honor of Peter Schmidt: Econometric Methods and Applications, Sickles, R. C. and W. C. Horrace (Eds). New York: Springer.

Anselin, L. (1988): Spatial Econometrics: Methods and Models. Dordrecht: Kluwer.

Bahar, D., R. Hausmann and C. A. Hidalgo (2014): 'Neighbors and the evolution of the comparative advantage of nations: Evidence of international knowledge diffusion?'. Journal of International Economics, vol. 92, pp. 111-123.

Battese, G. E. and T. J. Coelli (1992): 'Frontier production functions, technical efficiency and panel data: With application to paddy farmers in India'. Journal of Productivity Analysis, vol. 3, pp. $153-169$

Bottazzi, L. And G. Peri (2003): 'Innovation and spillovers in regions: Evidence from European patent data'. European Economic Review, vol. 47, pp. 687-710.

BlazeK, D. AND R. C. Sickles (2010): 'The impact of knowledge accumulation and geographical spillovers on productivity and efficiency: The case of U.S. shipbuilding during WWII'. Economic Modelling, vol. 27, pp. 1484-1497.

Branstetter, L. G. (2001): 'Are knowledge spillovers international in scope? Microeconometric evidence from the U.S. and Japan'. Journal of International Economics, vol. 53, pp. 53-79.

Chandra, A. And D. Staiger (2007): 'Productivity spillovers in health care: Evidence from the treatment of heart attacks'. Journal of Political Economy, vol. 115, pp. 103-140.

Chen, Y-Y., P. Schmidt And H-J. Wang (2014): 'Consistent estimation of the fixed effects stochastic frontier model'. Journal of Econometrics, vol. 181, pp. 65-76.

Cliff, A. D. And J. K. Ord (1973): Spatial Autocorrelation. London: Pion.

Cliff, A. D. And J. K. Ord (1981): Spatial Processes, Models and Applications. London: Pion.

Coe, D. T. and E. Helpman (1995): 'International R\&D spillovers'. European Economic Review, vol. 39, pp. 859-887.

Cornwell, C., P. Schmidt And R. C. Sickles (1990): 'Production frontiers with cross-sectional and time-series variation in efficiency levels'. Journal of Econometrics, vol. 46, pp. 185-200.

Druska, V. And W. C. Horrace (2004): 'Generalized moments estimation for spatial panel data: Indonesian rice farming'. American Journal of Agricultural Economics, vol. 86, pp. 185-198.

Duygun, M., J. HaO, A. Isaksson and R. C. Sickles (2015): 'Measuring world productivity'. Rice University, Mimeo.

Egger, P. and M. Pfaffermayr (2006): 'Spatial convergence'. Papers in Regional Science, vol. 85, pp. 199-215.

Elhorst, J. P. (2009): Spatial panel data models. In the Handbook of Applied Spatial Analysis, Fischer, M. M., and A. Getis (Eds). New York: Springer.

Elhorst, J. P. (2014): 'MATLAB software for spatial panels'. International Regional Science Review, vol. 37, pp. 389-405.

ERTur, C. And W. Koch (2007): 'Growth, technological interdependence and spatial externalities: Theory and evidence'. Journal of Applied Econometrics, vol. 22, pp. 1033-1062.

FAn, Y., Q. Li AND A. WeErsink (1996): 'Semiparametric estimation of stochastic production frontier models'. Journal of Business and Economic Statistics, vol. 14, pp. 460-468.

Feenstra, R. C., R. Inklaar and M. P. Timmer (2013a): 'The next generation of the Penn World Table'. Available at: www.ggdc.net/pwt

Feenstra, R. C., R. Inklaar and M. P. Timmer (2013b): 'PWT 8.0- a user guide'. Mimeo.

Fölster, S. And M. HenReKson (2001): 'Growth effects of government expenditure and taxation in rich countries'. European Economic Review, vol. 45, pp. 1501-1520.

GIRmA, S. (2005): 'Absorptive capacity and productivity spillovers from FDI: A threshold regression analysis'. Oxford Bulletin of Economics and Statistics, vol. 67, pp. 281-306.

Girma, S., H. Görg AND M. PISU (2008): 'Exporting, linkages and productivity spillovers from foreign direct investment'. Canadian Journal of Economics, vol. 41, pp. 320-340.

GIRMA, S. AND K. WAKELIN (2007): 'Local productivity spillovers from foreign direct investment in the U.K. electronics industry'. Regional Science and Urban Economics, vol. 37, pp. 399-412.

Glass, A. J., K. Kenjegalieva and J. Paez-Farrell (2013): 'Productivity growth decomposition using a spatial autoregressive frontier model'. Economics Letters, vol. 119, pp. 291-295. 
Glass, A. J., K. Kenjegalieva And R. C. Sickles (2014): 'Estimating efficiency spillovers with state level evidence for manufacturing in the US'. Economics Letters, vol. 123, pp. 154-159.

Greene, W. H. (1982): 'Maximum likelihood estimation of stochastic frontier production models'. Journal of Econometrics, vol. 18, pp. 285-289.

Greene, W. H. (1990): 'A gamma-distributed stochastic frontier model'. Journal of Econometrics, vol. 46, pp. 141-163.

Greene, W. H. (2005): 'Reconsidering heterogeneity in panel data estimators of the stochastic frontier model'. Journal of Econometrics, vol. 126, pp. 269-303.

InklaAR, R. And M. P. Timmer (2013): 'Capital, labor and TFP in PWT 8.0'. Mimeo.

Jondrow, J., C. A. K. Lovell, I. S. Materov and P. Schmidt (1982): 'On the estimation of technical inefficiency in the stochastic frontier production function model'. Journal of Econometrics, vol. 19, pp. 233-238.

KAO, Y-H. AND A. K. BERA (2013): 'Spatial regression: The curious case of negative spatial dependence'. University of Illinois, Urbana-Champaign, Mimeo.

Kauermann, G. and R. J. Carroll (2001): 'A note on the efficiency of sandwich covariance matrix estimation'. Journal of the American Statistical Association, vol. 96, pp. 1387-1396.

Kelejian, H. H. And I. R. PRUCha (1998): 'A generalized spatial two stage least squares procedure for estimating a spatial autoregressive model with autoregressive disturbances'. Journal of Real Estate Finance and Economics, vol. 17, pp. 99-121.

Kelejian, H. H. And I. R. PRUCha (1999): 'A generalized moments estimator for the autoregressive parameter in a spatial model '. International Economic Review, vol. 40, pp. 509-533.

Keller, W . (2002): 'Geographic localization of international technology diffusion'. American Economic Review, vol. 92, pp. 120-142.

Keller, W. And S. R. Yeaple (2013): 'The gravity of knowledge'. American Economic Review, vol. 103, pp. 1414-1444.

Kneip, A., R. C. Sickles And W. Song (2012): 'A new panel data treatment for heterogeneity in time trends'. Econometric Theory, vol. 28, pp. 590-628.

Koch, W. (2008): 'Development accounting with spatial effects'. Spatial Economic Analysis, vol. 3, pp. 321-342.

KumbhakAR, S. C. AND H-J. WANG (2005): 'Estimation of growth convergence using a stochastic production frontier approach'. Economics Letters, vol. 88, pp. 300-305.

LeSage, J. And R. K. Pace (2009): Introduction to Spatial Econometrics. Boca Raton, Florida: CRC Press, Taylor and Francis Group.

López-Bazo, E., E. VAyÁ And M. Artis (2004): 'Regional externalities and growth: Evidence from European regions'. Journal of Regional Science, vol. 44, pp. 43-73.

LiU, J., R. C. Sickles And E. G. Tsionas (2015): 'Bayesian treatments to panel data models with an application to models of productivity'. Rice University. Mimeo.

ORD, K. (1975): 'Estimation methods for models of spatial interaction'. Journal of the American Statistical Association, vol. 70, pp. 120-126.

PACE, R. K. AND R. BARRY (1997): 'Quick computation of spatial autoregressive estimators'. Geographical Analysis, vol. 29, pp. 232-247.

Pfaffermayr, M. (2009): 'Conditional $\beta$ - and $\sigma$-convergence in space: A maximum likelihood approach'. Regional Science and Urban Economics, vol. 39, pp. 63-78.

Pfaffermayr, M. (2013): 'The Cliff and Ord test for spatial correlation of the disturbances in unbalanced panel models'. International Regional Science Review, vol. 36, pp. 492-506.

Romer, P. M. (1987): Crazy explanations for the productivity slowdown. In the NBER Macroeconomics Annual 1987, Volume 2, Fischer, S. (Ed). Cambridge, MA: MIT Press.

Schmidt, P. And R. C. Sickles (1984): 'Production frontiers and panel data'. Journal of Business and Economic Statistics, vol. 2, pp. 367-374.

Sheather, S. J. And M. C. Jones (1991): 'A reliable data-based bandwith selection method for kernel density estimation'. Journal of the Royal Statistical Society. Series B, vol. 53, pp. 683-690.

Sickles, R. C., J. HaO And C. Shang (2015): Productivity and panel data. Chapter 17 of the Oxford Handbook of Panel Data, Baltagi, B. H. (Ed). New York: Oxford University Press, pp. 517-547.

Solow, R. M. (1956): 'A contribution to the theory of economic growth'. Quarterly Journal of Economics, vol. 70, pp. 65-94.

Solow, R. M. (1957): 'Technical change and the aggregate production function'. Review of Economics and Statistics, vol. 39, pp. 312-320.

Stevenson, R. (1980): 'Likelihood functions for generalized stochastic frontier estimation'. Journal of Econometrics, vol. 13, pp. 58-66. 
TAKII, S. (2005): 'Productivity spillovers and characteristics of foreign multinational plants in Indonesian manufacturing 1990-1995'. Journal of Development Economics, vol. 76, pp. 521-542.

Zimmerman, D. L. And D. A. Harville (1991): 'A random field approach to the analysis of field-plot experiments and other spatial experiments'. Biometrics, vol. 47, pp. 223-239. 

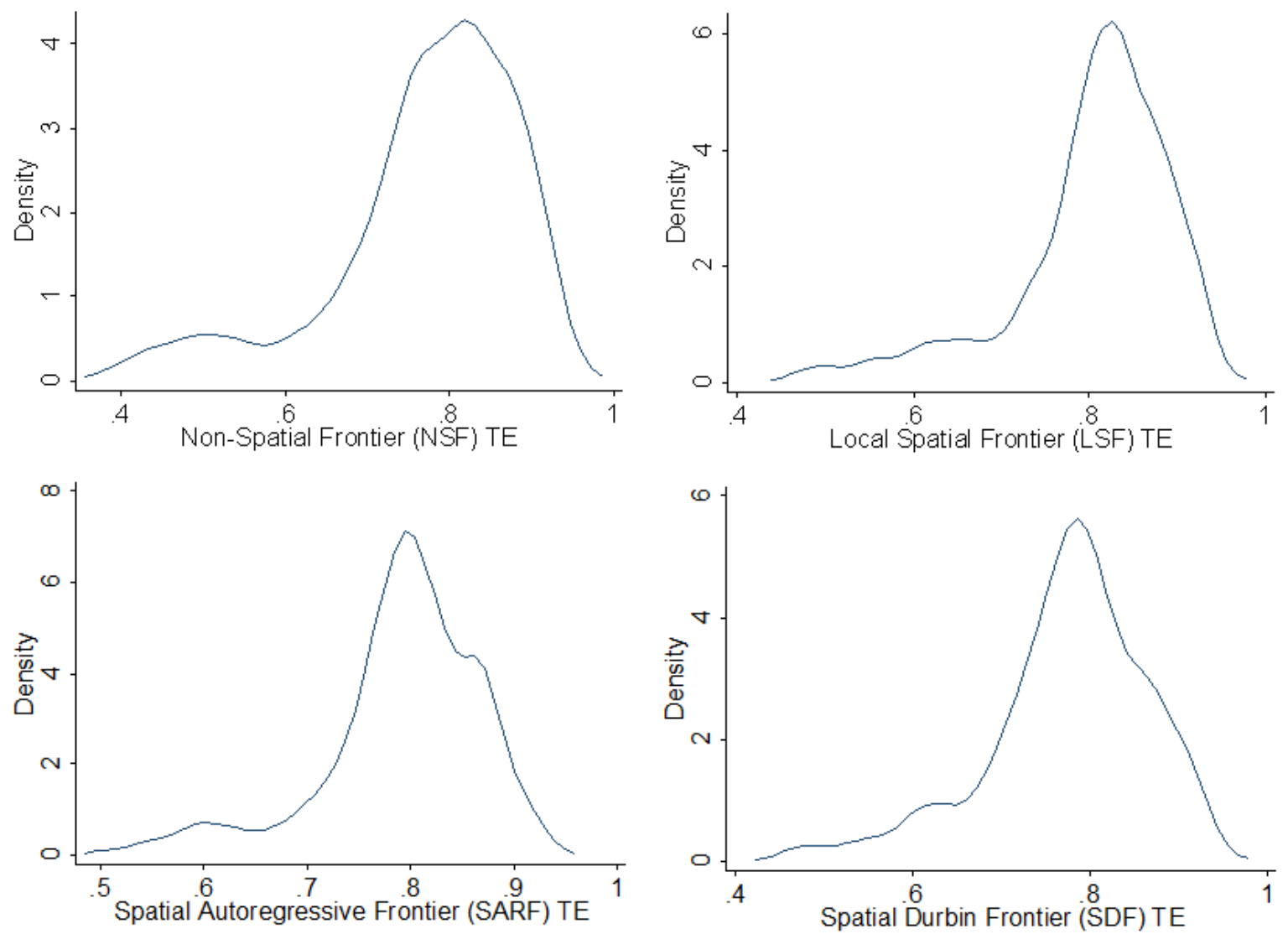

Figure 1: Kernel densities of the technical efficiencies

Table 1: Summary statistics

\begin{tabular}{lccccc}
\hline \hline & Variable & Mean & $\begin{array}{c}\text { Standard } \\
\text { Deviation }\end{array}$ & Minimum & Maximum \\
\hline \hline Real GDP (2005 million U.S. dollars at & $y$ & 366,380 & 589,103 & 4,049 & $2,982,019$ \\
2005 PPPs) & & & & & \\
Number of people engaged (millions) & $g_{1}$ & 8.41 & 13.04 & 0.13 & 75.46 \\
$\begin{array}{l}\text { Real capital stock (2005 million U.S. dollars } \\
\text { at current PPPs) }\end{array}$ & $g_{2}$ & $1,243,469$ & $2,128,382$ & 9,206 & $10,405,759$ \\
$\begin{array}{l}\text { Exports of merchandise minus imports of } \\
\text { merchandise as a share of GDP i.e. net }\end{array}$ & $z_{1}$ & -0.05 & 0.13 & -0.59 & 0.67 \\
trade openness & & & & 0.07 & 0.71 \\
Government spending as a share of GDP & $z_{2}$ & 0.22 & 0.08 & 0.07 \\
\hline
\end{tabular}


Table 2: Non-spatial, local spatial, spatial autoregressive and spatial Durbin frontiers

\begin{tabular}{|c|c|c|c|c|c|c|c|c|c|}
\hline & & \multicolumn{2}{|c|}{$\overline{\mathrm{NSF}}$} & \multicolumn{2}{|c|}{ LSF } & \multicolumn{2}{|c|}{ SARF } & \multicolumn{2}{|c|}{ SDF } \\
\hline & & Coef. & t-stat & Coef. & t-stat & Coef. & t-stat & Coef. & t-stat \\
\hline$g_{1}$ & $\varpi_{1}$ & $0.289^{* * *}$ & 15.32 & $0.320^{* * *}$ & $\bar{~} 16.04$ & $0.282^{* * *}$ & 15.55 & $0.302^{* * *}$ & 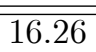 \\
\hline$g_{2}$ & $\varpi_{2}$ & $0.668^{* * *}$ & 36.19 & $0.633^{* * *}$ & 32.16 & $0.681^{* * *}$ & 39.69 & $0.653^{* * *}$ & 36.70 \\
\hline$t$ & $\eta_{1}$ & $-0.004^{*}$ & -2.52 & $-0.018^{* * *}$ & -6.18 & $-0.009 * * *$ & -5.49 & $-0.022^{* * *}$ & -7.50 \\
\hline$t^{2}$ & $\eta_{2}$ & $-0.001^{* * *}$ & -5.15 & $-0.002^{* * *}$ & -6.56 & $-0.001^{* * *}$ & -4.72 & $-0.001^{* * *}$ & -5.53 \\
\hline$z_{1}$ & $\psi_{1}$ & $0.631^{* * *}$ & 9.46 & $0.562^{* * *}$ & 8.19 & $0.560 * * *$ & 7.60 & $0.505^{* * *}$ & 6.88 \\
\hline$z_{2}$ & $\psi_{2}$ & $-1.616^{* * *}$ & -12.04 & $-1.500^{* * *}$ & -11.35 & $-1.660 * * *$ & -12.96 & $-1.493^{* * *}$ & -11.39 \\
\hline$z_{3}$ & $\psi_{3}$ & $0.165^{* * *}$ & 7.47 & $0.116^{* * *}$ & 5.25 & $0.171^{* * *}$ & 7.40 & $0.134^{* * *}$ & 6.03 \\
\hline$\left(I_{T} \otimes W\right) g_{1}$ & $\zeta_{1}$ & - & - & $-0.685^{* * *}$ & -5.57 & - & - & $-0.903^{* * *}$ & -7.48 \\
\hline$\left(I_{T} \otimes W\right) g_{2}$ & $\zeta_{2}$ & - & - & $0.340^{* * *}$ & 4.37 & - & - & $0.309^{* *}$ & 3.05 \\
\hline$\left(I_{T} \otimes W\right) z_{1}$ & $\theta_{1}$ & - & - & $1.663^{* * *}$ & 4.07 & - & - & $1.427^{* * *}$ & 3.45 \\
\hline$\left(I_{T} \otimes W\right) z_{2}$ & $\theta_{2}$ & - & - & $-4.395^{* * *}$ & -7.64 & - & - & $-3.792^{* * *}$ & -5.79 \\
\hline$\left(I_{T} \otimes W\right) y$ & $\delta$ & - & - & - & - & $0.217^{* * *}$ & 6.35 & $0.204^{*}$ & 2.28 \\
\hline Constant & $\kappa$ & $3.371^{* * *}$ & 14.54 & 1.259 & 1.41 & 0.627 & 1.06 & -0.868 & -1.21 \\
\hline$\overline{\lambda \lambda}$ & & 2.042 & & 1.594 & & 1.146 & & 1.528 & \\
\hline$\sigma^{2}$ & & 0.147 & & 0.114 & & 0.107 & & 0.110 & \\
\hline$\sigma_{u}$ & & $0 . .344$ & & 0.286 & & 0.175 & & 0.201 & \\
\hline$\overline{L L L}$ & & -71.355 & & -45.110 & & -70.930 & & -20.685 & \\
\hline$A I C$ & & 158.7 & & 114.2 & & 159.9 & & 67.4 & \\
\hline$B I C$ & & 197.1 & & 171.9 & & 203.1 & & 129.8 & \\
\hline
\end{tabular}

Notes: *,**,*** denote statistical significance at the 5\%,1\% and $0.1 \%$ levels, respectively.

LSF, SARF and SDF denote the local spatial, spatial autoregressive and spatial Durbin frontiers, respectively. $\mathrm{AIC}$ and BIC denote the Akaike and Bayesian Information Criteria, respectively. 
Table 3: Marginal effects for the spatial autoregressive frontier and spatial Durbin frontier

\begin{tabular}{lllllll}
\hline \hline \multicolumn{6}{c}{ Panel A: Marginal Effects for the SARF } \\
\hline \multicolumn{2}{c}{ Direct } & \multicolumn{2}{c}{ Indirect } & \multicolumn{2}{c}{ Total } \\
& \multicolumn{1}{c}{ Coef. } & t-stat & Coef. & t-stat & Coef. & t-stat \\
\hline$g_{1}$ & $0.286^{* * *}$ & 5.38 & $0.078^{* * *}$ & 5.33 & $0.364^{* * *}$ & 5.37 \\
$g_{2}$ & $0.681^{* * *}$ & 20.75 & $0.187^{* * *}$ & 21.08 & $0.868^{* * *}$ & 20.84 \\
$t$ & $-0.009^{* * *}$ & -5.27 & $-0.003^{* *}$ & -2.87 & $-0.012^{* * *}$ & -4.61 \\
$t^{2}$ & $-0.001^{* * *}$ & -4.76 & $0.000^{* *}$ & -3.23 & $-0.002^{* * *}$ & -4.59 \\
$z_{1}$ & $0.562^{* * *}$ & 8.75 & $0.154^{* * *}$ & 8.74 & $0.717^{* * *}$ & 8.75 \\
$z_{2}$ & $-1.667^{* * *}$ & -14.88 & $-0.457^{* * *}$ & -14.76 & $-2.125^{* * *}$ & -14.86 \\
$z_{3}$ & $0.172^{* * *}$ & 7.24 & $0.047^{* * *}$ & 4.29 & $0.219^{* * *}$ & 7.29 \\
\hline \hline
\end{tabular}

\begin{tabular}{lllllll}
\hline \hline \multicolumn{4}{c}{ Panel B: Marginal Effects for the SDF } \\
\hline & \multicolumn{2}{c}{ Direct } & \multicolumn{2}{c}{ Indirect } & \multicolumn{2}{c}{ Total } \\
& Coef. & t-stat & \multicolumn{1}{c}{ Coef. } & t-stat & Coef. & t-stat \\
\hline$g_{1}$ & $0.300^{* *}$ & 2.95 & $0.076^{* *}$ & 2.95 & $0.376^{* *}$ & 2.95 \\
$g_{2}$ & $0.652^{* * *}$ & 12.74 & $0.166^{* * *}$ & 12.67 & $0.818^{* * *}$ & 12.73 \\
$t$ & $-0.022^{* * *}$ & -7.48 & -0.006 & -1.80 & $-0.028^{* * *}$ & -6.18 \\
$t^{2}$ & $-0.002^{* * *}$ & -5.38 & 0.000 & -1.83 & $-0.002^{* * *}$ & -5.25 \\
$z_{1}$ & $0.511^{* * *}$ & 4.10 & $0.130^{* * *}$ & 4.10 & $0.640^{* * *}$ & 4.10 \\
$z_{2}$ & $-1.492^{* * *}$ & -8.91 & $-0.379^{* * *}$ & -8.92 & $-1.871^{* * *}$ & -8.91 \\
$z_{3}$ & $0.135^{* * *}$ & 6.04 & 0.036 & 1.74 & $0.171^{* * *}$ & 5.00 \\
\hline \hline
\end{tabular}

Notes: ${ }^{*},{ }^{*}, * * *$ denote statistical significance at the $5 \%, 1 \%$ and $0.1 \%$ levels, respectively.

SARF and SDF denote the spatial autoregressive frontier and spatial Durbin frontier, respectively.

Table 4: Average technical efficiencies and the associated rankings

\begin{tabular}{lcccccccc}
\hline \hline Country & \multicolumn{3}{c}{ NSF } & \multicolumn{3}{c}{ LSF } & \multicolumn{3}{c}{ SARF } & \multicolumn{2}{c}{ SDF } \\
& Av TE & Av TE Rank & Av TE & Av TE Rank & Av TE & Av TE Rank & Av TE & Av TE Rank \\
\hline \hline Albania & 0.544 & 40 & 0.589 & 41 & 0.659 & 39 & 0.564 & 41 \\
Armenia & 0.596 & 38 & 0.664 & 38 & 0.685 & 38 & 0.665 & 38 \\
Belarus & 0.669 & 36 & 0.755 & 34 & 0.731 & 36 & 0.736 & 32 \\
Cyprus & 0.738 & 32 & 0.827 & 17 & 0.767 & 31 & 0.800 & 16 \\
Czech Republic & 0.805 & 19 & 0.815 & 22 & 0.800 & 21 & 0.780 & 20 \\
United Kingdom & 0.900 & 2 & 0.875 & 5 & 0.861 & 6 & 0.838 & 8 \\
Greece & 0.763 & 25 & 0.833 & 15 & 0.802 & 19 & 0.798 & 17 \\
Ireland & 0.834 & 12 & 0.859 & 10 & 0.812 & 16 & 0.829 & 12 \\
Moldova & 0.572 & 39 & 0.654 & 39 & 0.652 & 40 & 0.650 & 39 \\
Norway & 0.908 & 1 & 0.911 & 2 & 0.883 & 2 & 0.896 & 2 \\
Portugal & 0.740 & 31 & 0.768 & 32 & 0.744 & 35 & 0.723 & 35 \\
Sweden & 0.857 & 6 & 0.867 & 7 & 0.850 & 8 & 0.836 & 9 \\
Slovenia & 0.758 & 27 & 0.795 & 28 & 0.785 & 26 & 0.755 & 27 \\
Ukraine & 0.526 & 41 & 0.622 & 40 & 0.627 & 41 & 0.610 & 40 \\
\hline
\end{tabular}

Notes: Average TE ranks are in descending order.

NSF, LSF, SARF and SDF denote the non-spatial, local spatial, spatial autoregressive and spatial Durbin frontiers, respectively. 
Table 5: Relative efficiencies for selected countries and the associated shares

\begin{tabular}{|c|c|c|c|c|c|c|c|}
\hline & & \multicolumn{3}{|c|}{ SARF } & \multicolumn{3}{|c|}{ SDF } \\
\hline & & Direct & Indirect & Total & Direct & Indirect & Total \\
\hline \multirow[t]{6}{*}{ Albania } & $R E_{i t}$ & $0.721(39)$ & $0.974(36)$ & $0.779(39)$ & $0.612(41)$ & $0.978(10)$ & $0.686(41)$ \\
\hline & $R E_{j t}$ & $0.721(39)$ & $0.743(11)$ & $0.775(33)$ & $0.612(41)$ & $0.745(10)$ & $0.690(38)$ \\
\hline & $R E_{i t}^{T o t}$ & $0.583(39)$ & $0.196(1)$ & & $0.505(41)$ & $0.181(1)$ & \\
\hline & $S R E_{i t}$ & 0.75 & 0.25 & & 0.73 & 0.27 & \\
\hline & $R E_{j t}^{T o t}$ & $0.560(39)$ & $0.215(11)$ & & $0.490(41)$ & $0.200(10)$ & \\
\hline & $S R E_{j t}$ & 0.72 & 0.28 & & 0.71 & 0.29 & \\
\hline \multirow[t]{6}{*}{ Armenia } & $R E_{i t}$ & $0.748(38)$ & $0.979(29)$ & $0.797(38)$ & $0.721(38)$ & $0.974(26)$ & $0.771(38)$ \\
\hline & $R E_{j t}$ & $0.748(38)$ & $0.375(38)$ & $0.690(41)$ & $0.721(38)$ & $0.375(38)$ & $0.678(40)$ \\
\hline & $R E_{i t}^{T o t}$ & $0.605(38)$ & $0.192(30)$ & & $0.595(38)$ & $0.177(26)$ & \\
\hline & $S R E_{i t}$ & 0.76 & 0.24 & & 0.77 & 0.23 & \\
\hline & $R E_{j t}^{T o t}$ & $0.582(38)$ & $0.108(38)$ & & $0.577(38)$ & $0.101(38)$ & \\
\hline & $S R E_{j t}$ & 0.84 & 0.16 & & 0.85 & 0.15 & \\
\hline \multirow[t]{6}{*}{ Czech Republic } & $R E_{i t}$ & $0.873(21)$ & $0.985(9)$ & $0.900(21)$ & $0.846(20)$ & $0.980(5)$ & $0.875(20)$ \\
\hline & $R E_{j t}$ & $0.873(21)$ & $0.790(6)$ & $0.908(12)$ & $0.846(20)$ & $0.787(6)$ & $0.888(15)$ \\
\hline & $R E_{i t}^{T o t}$ & $0.706(21)$ & $0.194(10)$ & & $0.698(20)$ & $0.178(6)$ & \\
\hline & $S R E_{i t}$ & 0.78 & 0.22 & & 0.80 & 0.20 & \\
\hline & $R E_{j t}^{T o t}$ & $0.679(21)$ & $0.228(6)$ & & $0.677(20)$ & $0.211(6)$ & \\
\hline & $S R E_{j t}$ & 0.75 & 0.25 & & 0.76 & 0.24 & \\
\hline \multirow[t]{6}{*}{ United Kingdom } & $R E_{i t}$ & $0.940(6)$ & $0.983(19)$ & $0.954(6)$ & $0.909(8)$ & $0.973(28)$ & $0.926(8)$ \\
\hline & $R E_{j t}$ & $0.940(6)$ & $0.611(26)$ & $0.908(11)$ & $0.909(8)$ & $0.608(26)$ & $0.891(13)$ \\
\hline & $R E_{i t}^{T o t}$ & $0.761(6)$ & $0.193(20)$ & & $0.750(8)$ & $0.176(28)$ & \\
\hline & $S R E_{i t}$ & 0.80 & 0.20 & & 0.81 & 0.19 & \\
\hline & $R E_{j t}^{T o t}$ & $0.732(6)$ & $0.177(26)$ & & $0.727(8)$ & $0.163(26)$ & \\
\hline & $S R E_{j t}$ & 0.81 & 0.19 & & 0.82 & 0.18 & \\
\hline \multirow[t]{6}{*}{ Moldova } & $R E_{i t}$ & $0.711(40)$ & $0.981(24)$ & $0.768(40)$ & $0.703(39)$ & $0.977(14)$ & $0.757(39)$ \\
\hline & $R E_{j t}$ & $0.711(40)$ & $0.621(25)$ & $0.733(37)$ & $0.703(39)$ & $0.620(25)$ & $0.729(35)$ \\
\hline & $R E_{i t}^{T o t}$ & $0.576(40)$ & $0.193(25)$ & & $0.580(39)$ & $0.177(14)$ & \\
\hline & $S R E_{i t}$ & 0.74 & 0.26 & & 0.76 & 0.24 & \\
\hline & $R E_{j t}^{T o t}$ & $0.554(40)$ & $0.180(25)$ & & $0.562(39)$ & $0.167(25)$ & \\
\hline & $S R E_{j t}$ & 0.75 & 0.25 & & 0.77 & 0.23 & \\
\hline \multirow[t]{6}{*}{ Slovenia } & $R E_{i t}$ & $0.858(26)$ & $0.988(4)$ & $0.888(26)$ & $0.820(26)$ & $0.977(13)$ & $0.853(27)$ \\
\hline & $R E_{j t}$ & $0.858(26)$ & $0.838(4)$ & $0.910(10)$ & $0.820(26)$ & $0.832(4)$ & $0.879(16)$ \\
\hline & $R E_{i t}^{T o t}$ & $0.694(26)$ & $0.194(5)$ & & $0.676(26)$ & $0.177(13)$ & \\
\hline & $S R E_{i t}$ & 0.78 & 0.22 & & 0.79 & 0.21 & \\
\hline & $R E_{j t}^{T o t}$ & $0.668(26)$ & $0.242(4)$ & & $0.656(27)$ & $0.223(4)$ & \\
\hline & $S R E_{j t}$ & 0.73 & 0.27 & & 0.75 & 0.25 & \\
\hline \multirow[t]{6}{*}{ Norway } & $R E_{i t}$ & $0.964(3)$ & $0.973(37)$ & $0.970(3)$ & $0.965(3)$ & $0.969(34)$ & $0.972(3)$ \\
\hline & $R E_{j t}$ & $0.964(3)$ & $0.473(32)$ & $0.887(20)$ & $0.965(3)$ & $0.474(32)$ & $0.899(12)$ \\
\hline & $R E_{i t}^{T o t}$ & $0.779(3)$ & $0.191(37)$ & & $0.796(3)$ & $0.176(34)$ & \\
\hline & $S R E_{i t}$ & 0.80 & 0.20 & & 0.82 & 0.18 & \\
\hline & $R E_{j t}^{T o t}$ & $0.750(3)$ & $0.137(32)$ & & $0.772(3)$ & $0.127(32)$ & \\
\hline & $S R E_{j t}$ & 0.85 & 0.15 & & 0.86 & 0.14 & \\
\hline \multirow[t]{6}{*}{ Ukraine } & $R E_{i t}$ & $0.685(41)$ & $0.980(27)$ & $0.746(41)$ & $0.659(40)$ & $0.977(15)$ & $0.722(40)$ \\
\hline & $R E_{j t}$ & $0.685(41)$ & $0.595(29)$ & $0.705(40)$ & $0.659(40)$ & $0.596(28)$ & $0.688(39)$ \\
\hline & $R E_{i t}^{T o t}$ & $0.554(41)$ & $0.192(28)$ & & $0.544(40)$ & $0.177(15)$ & \\
\hline & $S R E_{i t}$ & 0.74 & 0.26 & & 0.75 & 0.25 & \\
\hline & $R E_{j t}^{T o t}$ & $0.533(41)$ & $0.172(29)$ & & $0.528(40)$ & $0.160(28)$ & \\
\hline & $S R E_{j t}$ & 0.75 & 0.25 & & 0.76 & 0.24 & \\
\hline
\end{tabular}

Notes: Average RE ranks are in parentheses, where the ranks are in descending order.

SARF and SDF denote the spatial autoregressive and spatial Durbin frontiers, respectively. 